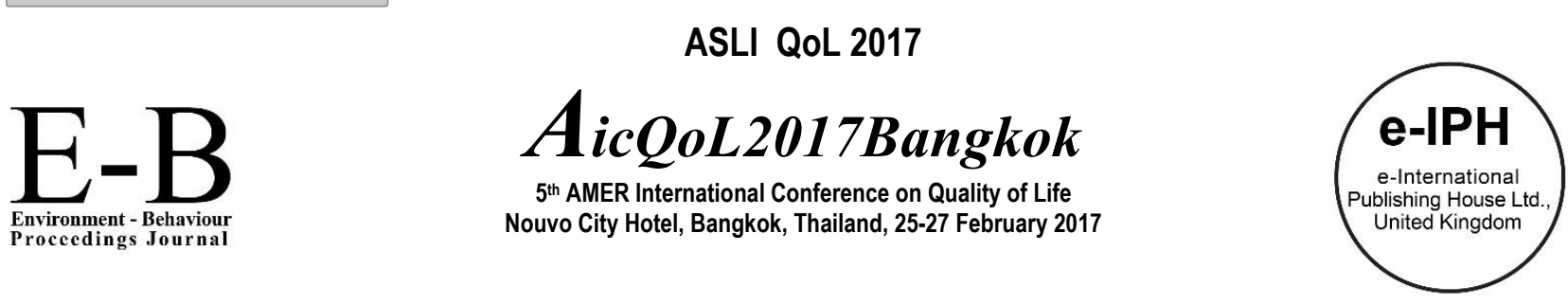

\title{
Environmental Graphic Design and the Travelers' Perception on the Exit Patterns of Subway Stations in Bangkok
}

\author{
Pakachart Puttipakorn ${ }^{1 *}$, Prapatpong Upala ${ }^{2}$ \\ ${ }^{1}$ Arch.D. Student, Multidisciplinary Design Research Program, \\ Faculty of Architecture, King Mongkut's Institute of Technology Ladkrabang (KMITL), Thailand \\ ${ }^{2}$ Ph.D., Faculty of Architecture, King Mongkut's Institute of Technology Ladkrabang (KMITL), Thailand
}

\begin{abstract}
The purpose of this study was to investigate the design of the exit of MRT Subway, Chalerm Ratchamongkol route. The physical analysis indicated that the station could be grouped the physical design into four categories of total 18 stations. Which have evidence many differences in physical characteristics and may cause problem and confusion in gestalt theory routing for passengers. These finding showed that the graphic design and elements which will lead to the displaying of directional information to guide the path for travelers to decide to the exit of each side.

Keywords: Environmental Graphic Design; Signage; Way-finding; Mass transit station.

ISSN: 2398-4287@ 2017. The Authors. Published for AMER ABRA by e-International Publishing House, Ltd., UK. This is an open access article under the CC BYNC-ND license (http://creativecommons.org/licenses/by-nc-nd/4.0/). Peer-review under responsibility of AMER (Association of Malaysian Environment-Behaviour Researchers), ABRA (Association of Behavioural Researchers on Asians) and CE-Bs (Centre for Environment-Behaviour Studies), Faculty of Architecture, Planning \& Surveying,
\end{abstract} Universiti Teknologi MARA, Malaysia.

\subsection{Introduction}

The signage design with Environmental Design is essential for the lead throughout of the route is imperative, especially crown spaces, such as sports stadium, mass transit station. The Environmental Graphic Design, especially signage (Weisman, 1981), can help the travelers for convenience (Bohari, 2014). The EGD be able to guide the direction for persons when they are in an important and complex area to reach the destination through the Directional Graphic system. Therefore, the design of the sufficient number of signage for way-finding system to passengers finds the path (JC Chebat, 2008) and way-finding to come to the goal by Self-Guiding System is one of the major factors that for the complicated mass transportation (Zheng, 2009).

The 18 stations of Mass Rapid Transit (MRT) in Bangkok, Chalerm Ratchamongkol route (MRT), have a similar model for the same standard, so they were confused for passengers to remember and understand the environment around them. Because they are unable to make people for the notice and direction of the environment around them. From the comparison study of travel between electric train stations that are above ground and underground, which have different environmental factors of the five image elements (landmarks, paths, districts, edges, nodes) (Lynch, 1960) and effects on the mental image of passengers related to the recognition of their surroundings, passengers traveling by subway lack the surrounding factor, which results in difficulty of remembering the routes caused by the lack of ability to observe the direction of their surroundings. It is necessary to depend on directional signs or informational signs to guide the way and confirm that the route is correct throughout the travel (Zheng, 2012). Therefore, signage is important because passengers tend to remain more still in a subway station than when on an electric train platform above ground, which will stop only when there is a change of route affecting the overall traffic flow while traveling (Pontikakis, Twaroch, 2006). Moreover, areas that have different environments have different signage which affects the passengers' behavior. To facilitate convenience for traveling, designing of sufficient and suitable sign symbols for a way-finding system that helps passengers find their path and guides passengers to their destinations on their own (Self-Guiding System) is a major factor in a mass transportation system.

\footnotetext{
${ }^{*}$ Corresponding author. Tel.: +6685-3656-455

E-mail address: pakachart@gmail.com
}

ISSN: 2398-4287@ 2017. The Authors. Published for AMER ABRA by e-International Publishing House, Ltd., UK. This is an open access article under the CC BYNC-ND license (http://creativecommons.org/licenses/by-nc-nd/4.0/). Peer-review under responsibility of AMER (Association of Malaysian Environment-Behaviour Researchers), ABRA (Association of Behavioural Researchers on Asians) and CE-Bs (Centre for Environment-Behaviour Studies), Faculty of Architecture, Planning \& Surveying, Universiti Teknologi MARA, Malaysia.

DOI: http://dx.doi.org/10.21834/e-bpj.v2i5.620 
Signage is a part of the environmental design (Chermayeff, Calori, 2007) which guides people in large and complex areas to reach their destinations by using a directional graphic system.

This paper is the exploratory research. The aim of this study was to investigate the design of the exit of MRT Subway, Chalerm Ratchamongkol route which has a total routing distance of 20 kilometers, having 18 stations. Finding the relationship of the design within the exit of subway stations that affects the graphic design, elements, layout and the letters on the signage which will lead to the displaying of directional information to guide the path for passengers to decide to the exit of each side. Which have evidence many differences in physical characteristics, the number of doors and exit design of subway stations which has the difference and effects for the graphic layout and element, design position in displaying on signage which may cause problem and confusion in gestalt theory toward the recognition of information and the clarity of routing for passengers. This investigation was a survey investigation of the physical factors of the underground system in Bangkok in regard to the environmental graphic design that affected passengers' behaviour and exit route selection. It did not include a study of effectiveness of passengers' recognition and memorization of exit route.

\subsection{Way-finding System}

The way-finding is the ability of a person to reach a destination by the cognitive process which organizes the information that is received from the physical surrounding to cognitive process in mind and for spatial orientation from an empty place of self in space. (Passini,1984). The way-finding process is a psychological or environmental psychological process and cognitive mapping process which result in the cognitive mapping or image, which is a mental structure and factor of environmental perception and cognition. It was discovered that the results of the way-finding process had the same characteristics of a cognitive map, which is the conclusion of thought or representation of an empty space and map of that environment. The process that leads to the cognitive map consists of factors of the way-finding process such as environmental information, decision, and behavioral action. The decision process is a significant step which connects the mental information together and leads to behavioral expression. The way-finding process can be explained regarding of spatial problem solving which consists of the following processes (Arthur and Passini, 1992).

1) Decision Making such as action plan which helps to plan the action and understand the overall structure of the environment.

2) Decision Execution such as a change from the plan to action which changes the form of the decision to behavioral expression, where supporting information for the decision execution partly comes from the cognitive map.

3) Information Process such as understanding the information from the two previous decisions in terms of the environmental perception and cognition, see Fig. 1

\section{WAY-FINDING PROCESS}

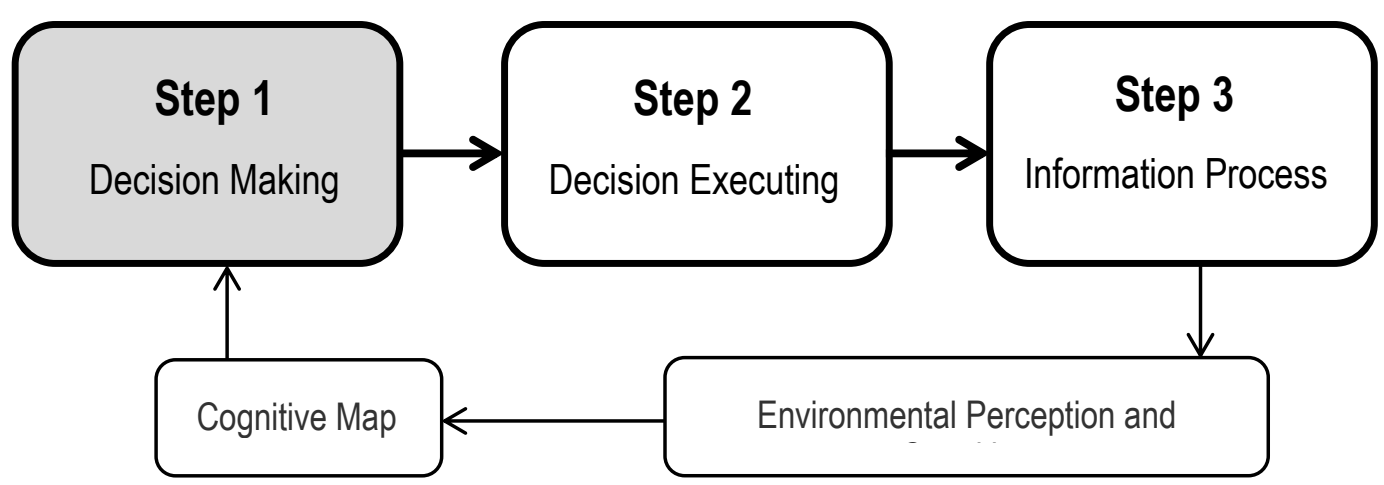

Fig. 1: Diagram displaying the way-finding process.

The way-finding relates to the connection of past experiences, effort to try to understand the environment, cognitive characteristics of the signs, maps, and indicators by also considering the factors of time, interest, and safety for using the way. The cognition of information from the environment consists of the planning process before action, which includes specifying Where to go, How to go, and When to go affecting the decision by which the decision process is organized in the form of hierarchy and requires environmental information. Starting from determining the destination and deciding to act in a sequence until reaching the destination, familiarity of the environment affects decisions on the way to a destination such that travelling to a target under familiar environmental circumstances can be decided by referring to a plan that was made in the past (Arthur and Passini, 1992).

\subsection{Visual Perception}

\subsubsection{Perception}


The visual perception by feeling results from stimuli all around that effects and causes perception without analyzing the information a human can sense through the five senses sight, sound, smell, touch and taste transfer to the brain resulting in the perception of feeling. Therefore, each person who perceives the same stimulus may interpret the information differently by using their existing experiences. Gestalt theory states that cognition of the whole is greater than the sum of its parts must come from an existing experience and study, The laws of the organization are as follows (Crooks \& Stein,1988).

- Law of Similarity is the principle of organizing graphical factors to help humans to perceive sight quickly. This law is similar and has the purpose of emphasizing important factors to stand out from other factors to compare shape, size, and color which are similar in concrete or abstract form, perceived to be the same thing or the same type by humans.

- Law of Proximity is the principle of organizing minor graphical factors relating to each other to be in a proximate location or a group which creates the visual image or communicates meaning. The law of proximity is used to increase the potential of visual images to communicate meaning.

- Law of Continuity is the principle of organizing graphical factors by ordering image factors in order of importance according to the way people read directions in different cultures, which is mostly from left to right and top to bottom. The organization of factors of continuity helps to pass on information that is in order. The law of continuity helps to organize these factors by ordering important information for clear and complete communications.

- Law of Closure is the principle of organizing graphical factors by emphasizing the reduction of images because in general, people are more familiar with reading an image that is complete than reading an image that is incomplete. If we have a full original image already recorded in our brain, we can then perceive the image partially but understand the image that is missing by using the image stored in our brain to complete the missing image.

\subsubsection{Insight}

The Self-learning results in the concept of learning or problem solving, which occurs instantly in seeing the way to solve a problem in order from beginning to end. Seeing the event in a new perspective is the result of understanding and sensing the event that is recognized (Lester, Martin Paul, 2000), which reveals the way to solve the problem instantly. By the ability to solve the problem with insight and seeing the relationship between things that exist, when people learn to solve a problem by insight and see how to do it, in their next encounter, they can solve behavior problems that are harder and harder with more completion.

\subsection{Research Methodology}

\subsection{Research Sampling}

This research sampling uses the method of purposive sampling to obtain a sampling group with the required characteristics such as: The projects of the electric train for mass transit in Thailand are categorized by service into three categories as follows:

- Metropolitan Rapid Transit Chaloem Ratchamongkhon Line (MRT) is an underground electric train project with a total service distance of 20 kilometers and 18 underground stations.

- Bangkok mass transit system (BTS) is an aboveground electric train project with a total service distance of 36.9 kilometers and 34 above ground stations.

- Airport Rail Link electric train is an aboveground electric train project that connects with Suvarnabhumi Airport and has a total service distance of 28 kilometers and 8 above ground stations.

Table 1. The types of travel for mass transit electric train projects in Thailand.

\begin{tabular}{llll}
\hline Type & Electric train & Environment & Stations \\
\hline 1 & Metropolitan Rapid Transit (MRT) & Underground & 18 \\
2 & Bangkok Mass Transit System (BTS) & Aboveground & 34 \\
3 & Electric train connecting Suvarnabhumi airport (Airport Rail Link) & Aboveground & 8 \\
\hline
\end{tabular}

Physical factors are important for recognizing the way, behaviors to recognize the information by limited environment and differences in environmental factors (Lynch, 1960) of the subway station, remembering the way is difficult because there are no surrounding points that are noticeably significant like in the case of aboveground stations. Therefore, it is an important reason for depending on the signage system to give directions for the destination. This was the basis for the researchers to choose the electric mass transit train of Metropolitan Rapid Transit Chaloem Ratchamongkhon Line (MRT) for this survey area.

\subsection{Study Area}

Metropolitan Rapid Transit Chaloem Ratchamongkhon Line (MRT) has a total route distance of 20 kilometers and is an underground project containing all the routes of 18 total stations, with an average distance of 1 kilometer between each station, starting from the front of Hua Lamphong railway station and ending at Bang Sue electric train station. The 18 stations are Hua Lamphong, Sam Yan, Si 
Lom, Lumphini, Khlong Toei, Queen Sirikit National Convention Centre, Sukhumvit, Phetchaburi, Phra Ram 9, Thailand Cultural Centre, Sutthisan, Huai Khwang, Ratchadaphisek, Lat Phrao, Phahon Yothin, Chatuchak Park, Kamphaeng Phet, and Bang Sue, as shown in route diagram below (Fig.2)

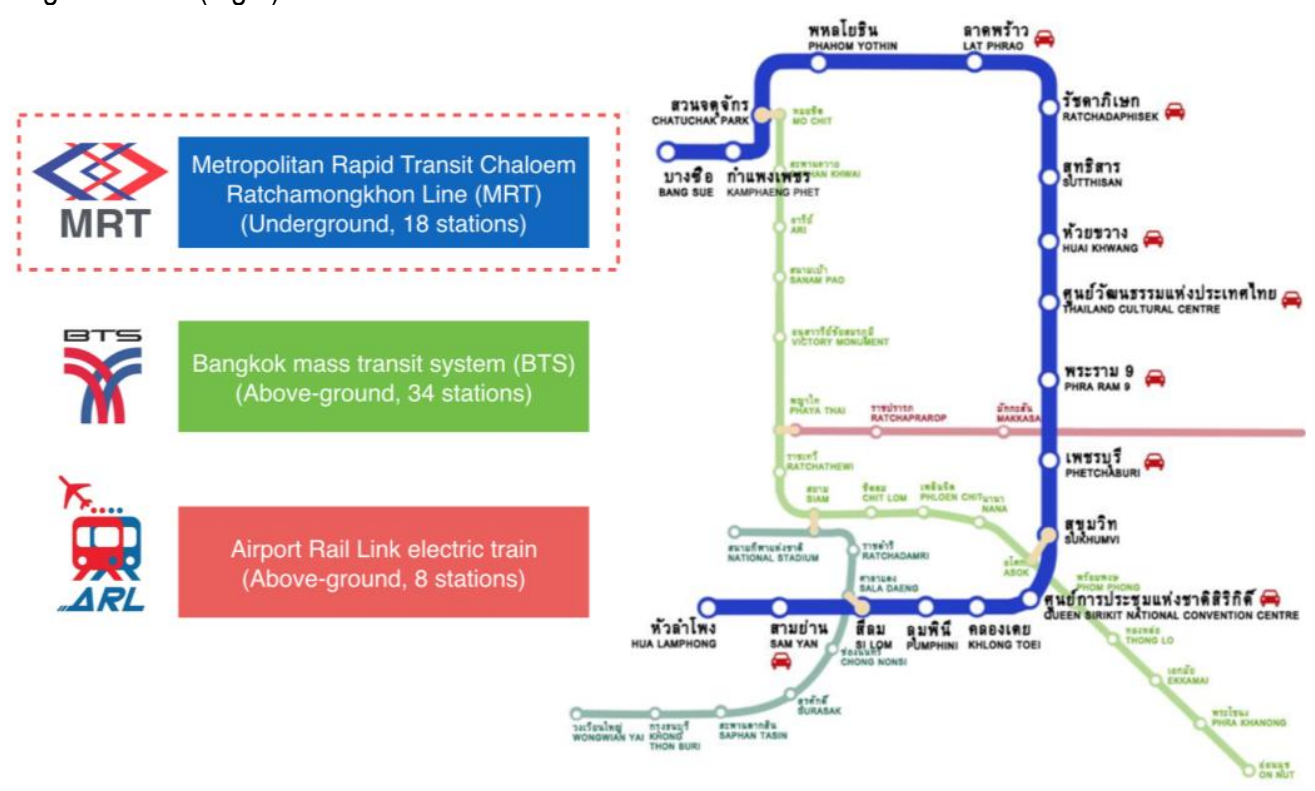

Fig. 2: Route diagram of Metropolitan Rapid Transit Chaloem Ratchamongkhon Line (MRT)

\subsection{Research Framework}

(Source: Bangkok Expressway and Metro public Limited.)

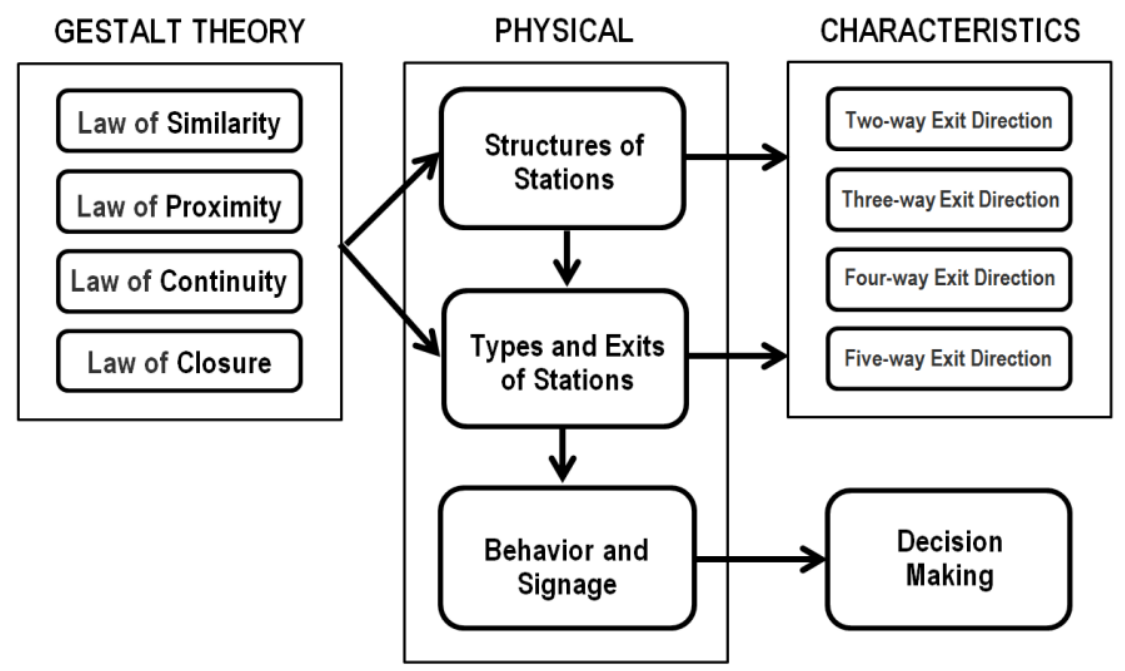

Fig.3: The diagram showing the relationship of variables in the study.

\subsection{Physical Analysis}

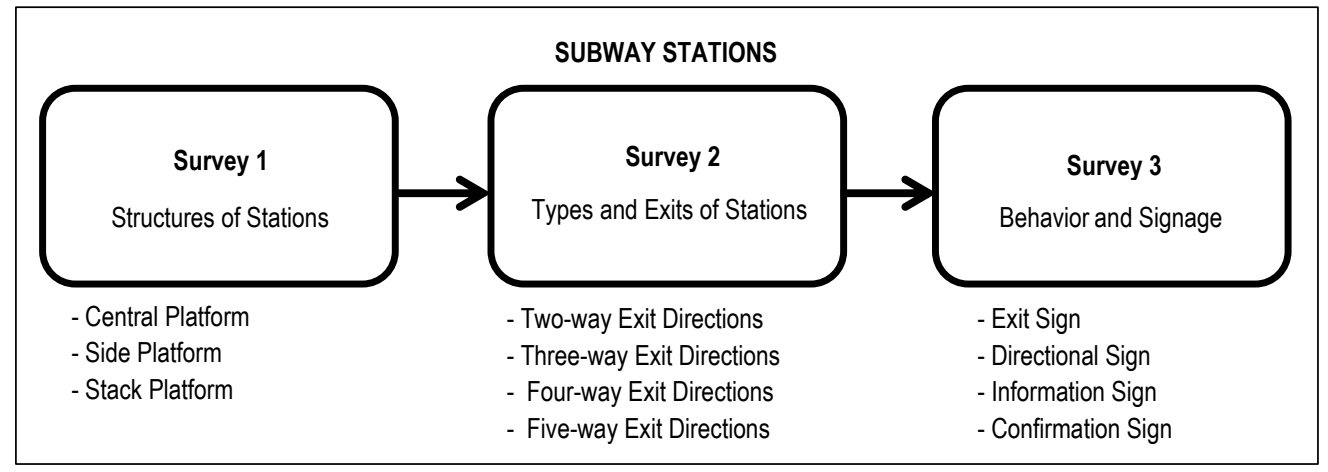

Fig. 4: The area survey of MRT station is divided into three characteristics which are structures of the stations, types, and exits of station and behavior and signage. 


\subsection{Structures of subway stations}

There are a total of 18 subway stations categorized into three types which are 1) Central platform 2) Side platform 3) Stack platform. The characteristic of each platform depends primarily on their physical limitations. A general station contains a shop level, ticket selling level, and platform level with a general length of $150-200$ meters and a general width of $15-25$, with a station roof depth from the ground surface of 1.5 - 3 meters and a depth of the platform to the road surface of 15 - 25 meters, depending on the characteristics of the platform and surrounding geography. Most stations are a central platform where the railways are located on each side of the platform, except in some areas which have stack platforms where the railways are on different levels divided into 3 types: 2 level structure, 3 level structure, and 4 level structure, which have platform screen doors, lifts, and escalators, see Fig. 5 and Fig. 6

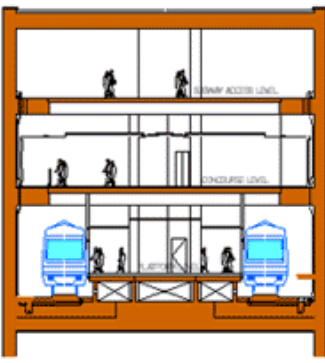

(a)

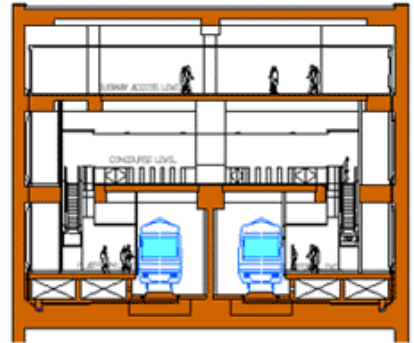

(b)

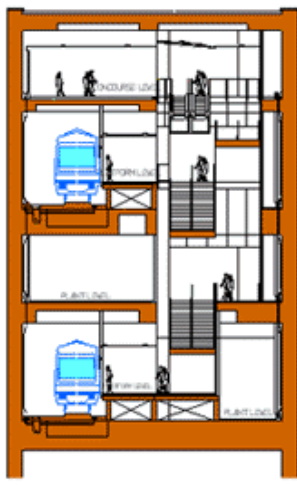

(c)

Fig. 5: (a) Central platform; (b) Side platform; (b) Stack platform. (Source: Bangkok Expressway and Metro public Limited.)

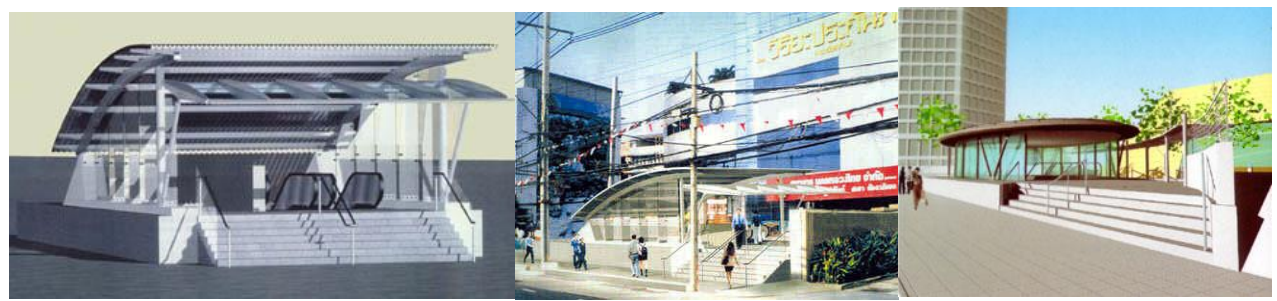

Fig. 6: The exits outside of subway stations.

(Source: Bangkok Expressway and Metro public Limited.)

\subsection{Type and exits of subway stations}

Categorization of specific environmental characteristics of the area according to the characteristic and the exits of the subway station can be divided into four groups as follows:

- Characteristic 1) Subway stations that have 2 paths and exits which include 4 stations: Si Lom, Sam Yan, Bang Sue, and Khlong Toei.

- Characteristic 2) Subway stations that have 3 paths and exits which include 5 stations: Sukhumvit, Phra Ram 9, Phetchaburi, Lumphini, and Kamphaeng Phet.

- Characteristic 3) Subway stations that have 4 paths and exits which include 8 stations: Huai Khwang, Lat Phrao, Chatuchak Park, Hua Lamphong, Queen Sirikit National Convention Centre, Thailand Cultural Centre, Suthisan, and Ratchadaphisek.

- Characteristic 4) Subway stations that have 5 paths and exits which include 1 station: Phahon Yothin.

Stations in the Metropolitan Rapid Transit Chaloem Ratchamongkhon Line (MRT) divided according to exit way in order of stations with the most to least passengers (statistical data of the passengers who used the service in 2014), see Table 2 and Fig. 7

Table 2. Stations in the Metropolitan Rapid Transit Chaloem Ratchamongkhon Line (MRT)

\begin{tabular}{|c|c|c|c|}
\hline Characteristic & Exit direction & Subway station & Total \\
\hline 1 & 2 ways & Si Lom, Sam Yan, Bang Sue, Khlong Toei. & 4 \\
\hline 2 & 3 ways & Sukhumvit, Phra Ram 9, Phetchaburi, Lumphini, Kamphaeng Phet. & 5 \\
\hline 3 & 4 ways & $\begin{array}{l}\text { Huai Khwang, Lat Phrao, Chatuchak Park, Hua Lamphong, Queen Sirikit National } \\
\text { Convention Centre, Thailand Cultural Centre, Sutthisan, Ratchadaphisek. }\end{array}$ & 8 \\
\hline \multirow[t]{2}{*}{4} & 5 ways & Phahon Yothin. & 1 \\
\hline & & total & 18 \\
\hline
\end{tabular}




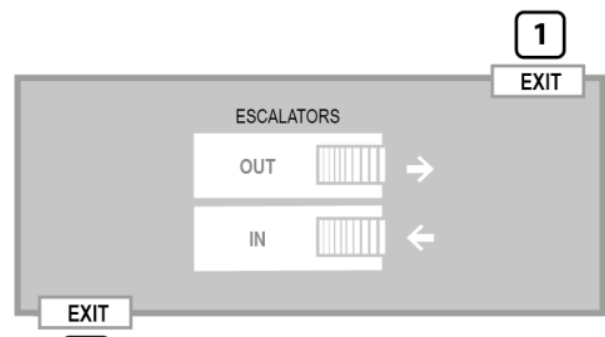

2

(a)

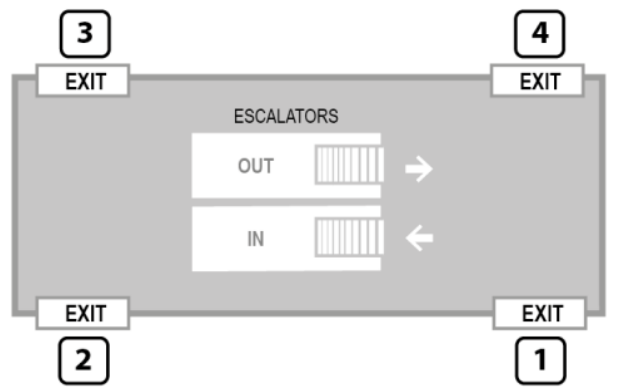

(c)

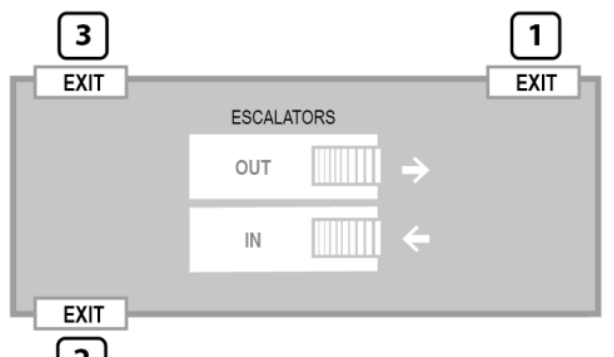

(b)

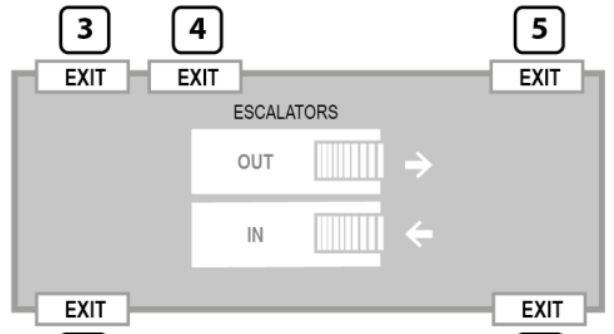

2

(d)

7. The exits of the subway station are divided into 4 categories;

(a) Two-way directions (Si Lom); (b) Three-way directions (Sukhumvit);

(c) Four-way directions (Huai Khwang); (d) Five-way directions (Phahon Yothin).

\section{Stations in the Metropolitan Rapid Transit Chaloem Ratchamongkhon Line (MRT)}

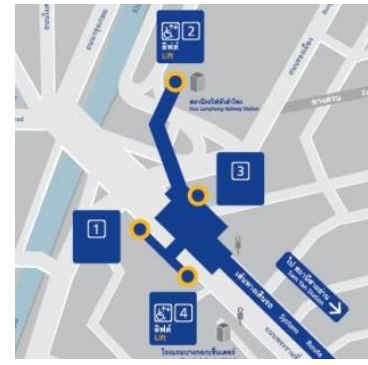

(a)

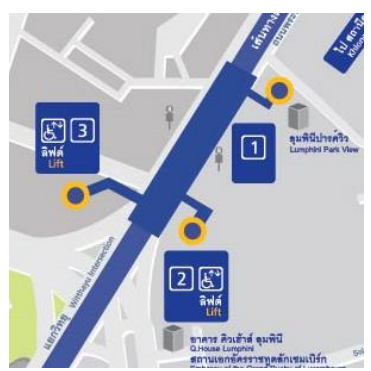

(d)

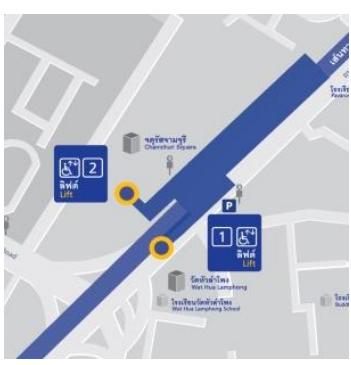

(b)

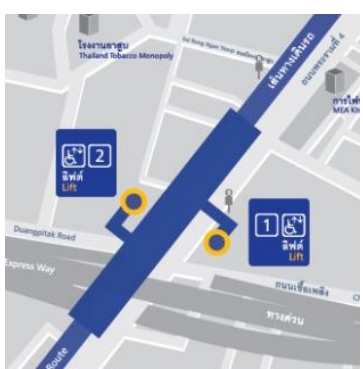

(e)

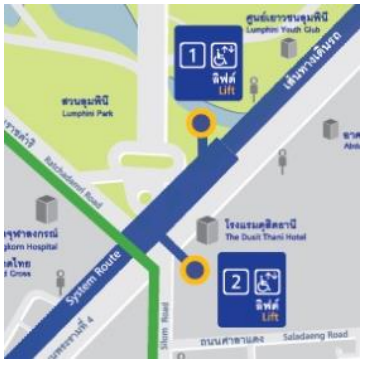

(c)

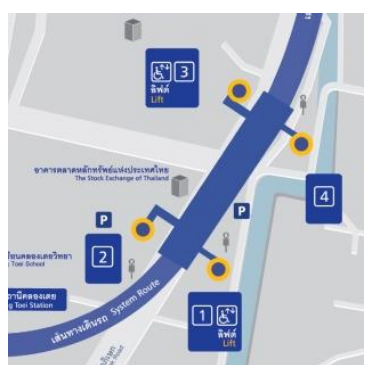

(f) 


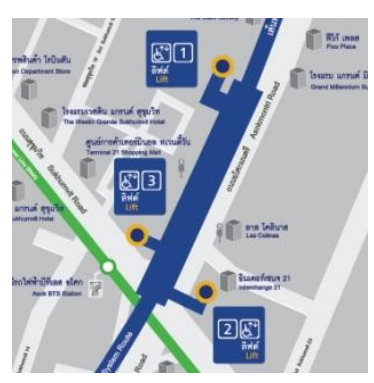

(g)

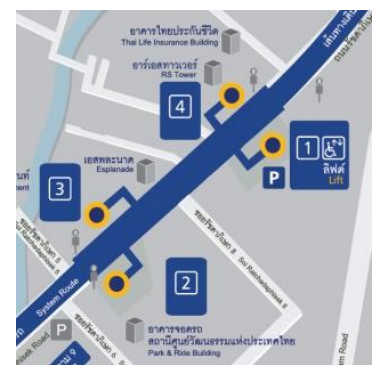

(j)

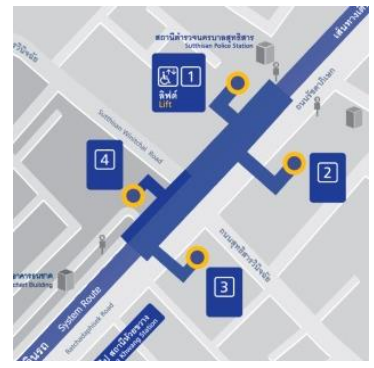

(m)

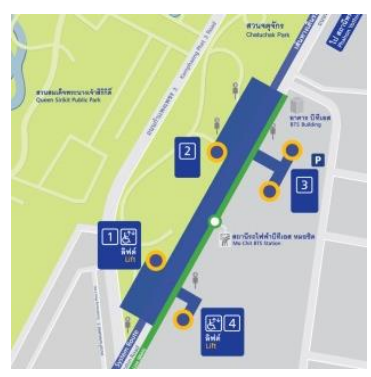

(p)

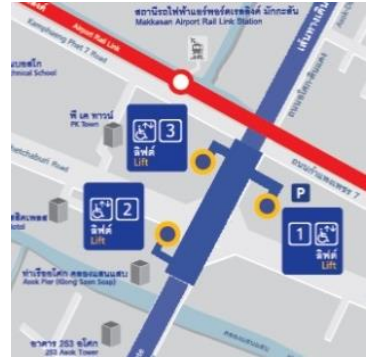

(h)

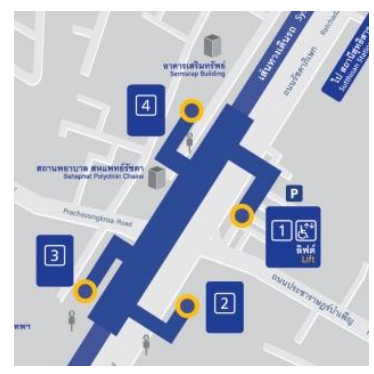

(k)

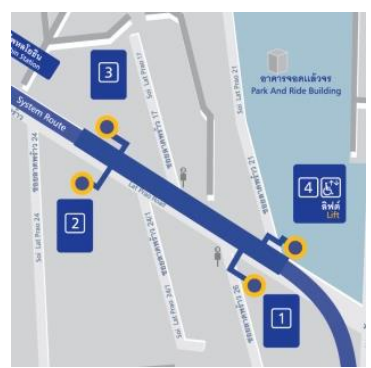

(n)

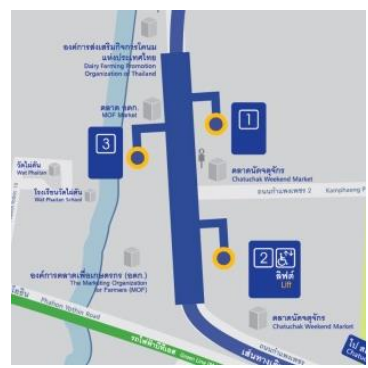

(q)

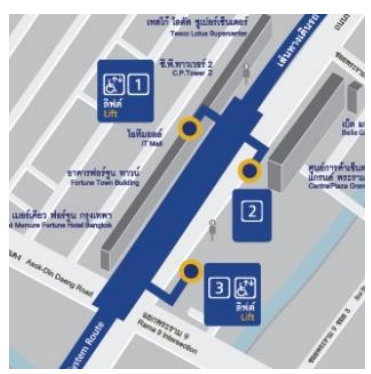

(i)

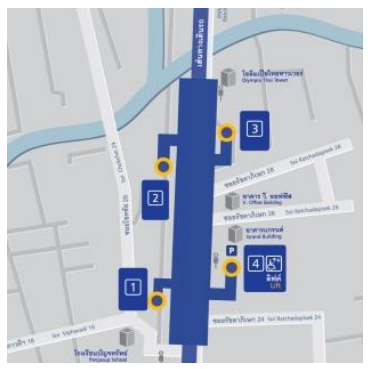

(l)

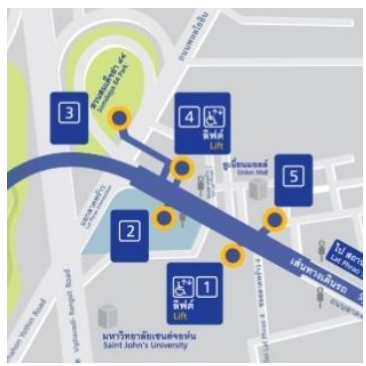

(0)

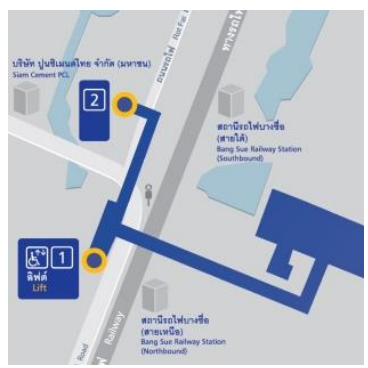

$(r)$

Fig. 8: Plan of Stations in the Metropolitan Rapid Transit Chaloem Ratchamongkhon Line (MRT);

(a) Hua Lamphong; (b) Sam Yan; (c) Si Lom;

(d) Lumphini; (e) Khlong Toei; (f) Queen Sirikit National Convention Centre;

(g) Sukhumvit; (h) Phetchaburi; (i) Phra Ram 9;

(j) Thailand Cultural Centre; (k) Sutthisan; (I) Huai Khwang;

(m) Ratchadaphisek; (n) Lat Phrao; (o) Phahon Yothin;

(p) Chatuchak Park; (q) Kamphaeng Phet; and (r) Bang Sue.

(Source: Bangkok Expressway and Metro public Limited.)

\subsection{Behavior and Signage}

Signs and pictorial symbols have the purpose of being used and being part of the way-finding system. The signage system is a part of the environmental design which is a system that helps to guide people in large and complex areas to reach their destination using the directional graphic system. Signage can be divided by beneficial use into four types which are Directional, Identifying, Informational, and Restrictive or Prohibitive, which facilitate the travel of passengers to their destinations quickly and effectively. From the traveling 
behavior of passengers, 4 steps can be identified according to the behavioral characteristics and the relationships between signage as follows:

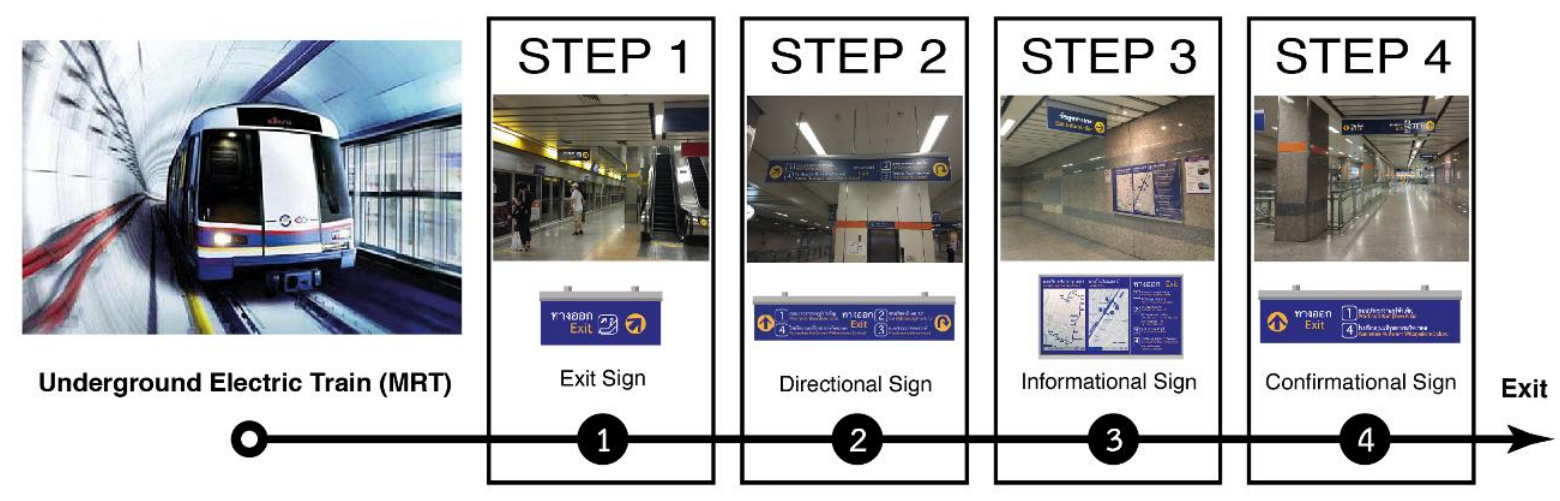

Fig. 9: The diagram steps of behavior and the relationships between signage.

Step 1 Exit sign - Passengers exit from the subway to the escalators.
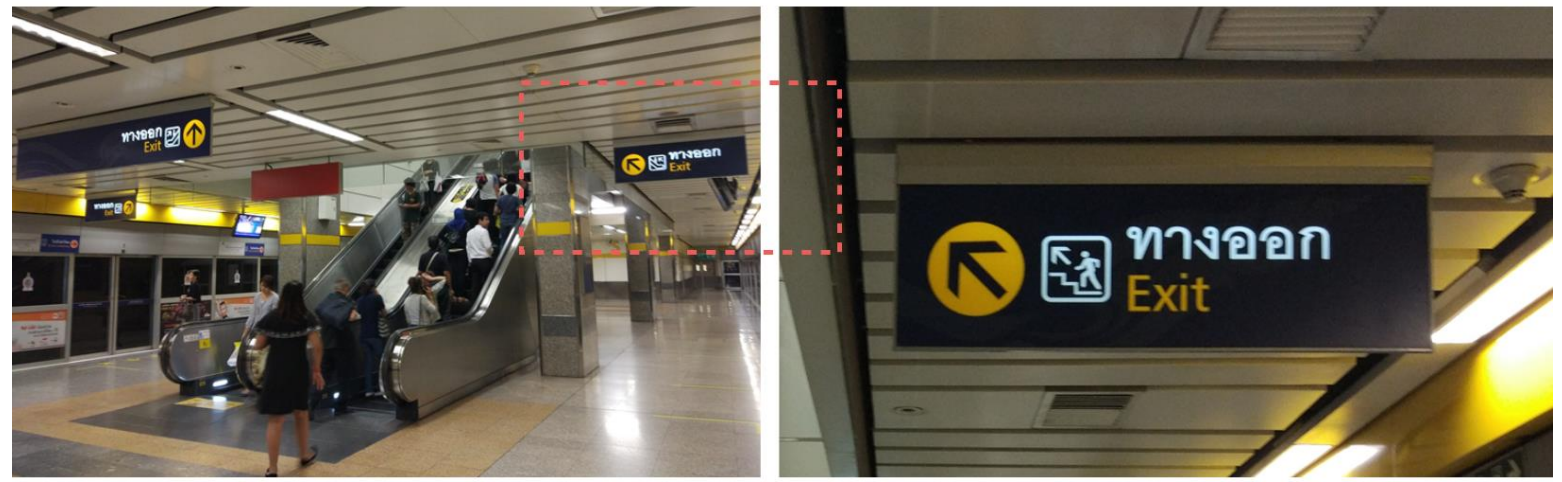

Step 2 Directional sign - Passengers choose numbers of exit gates from the escalators.
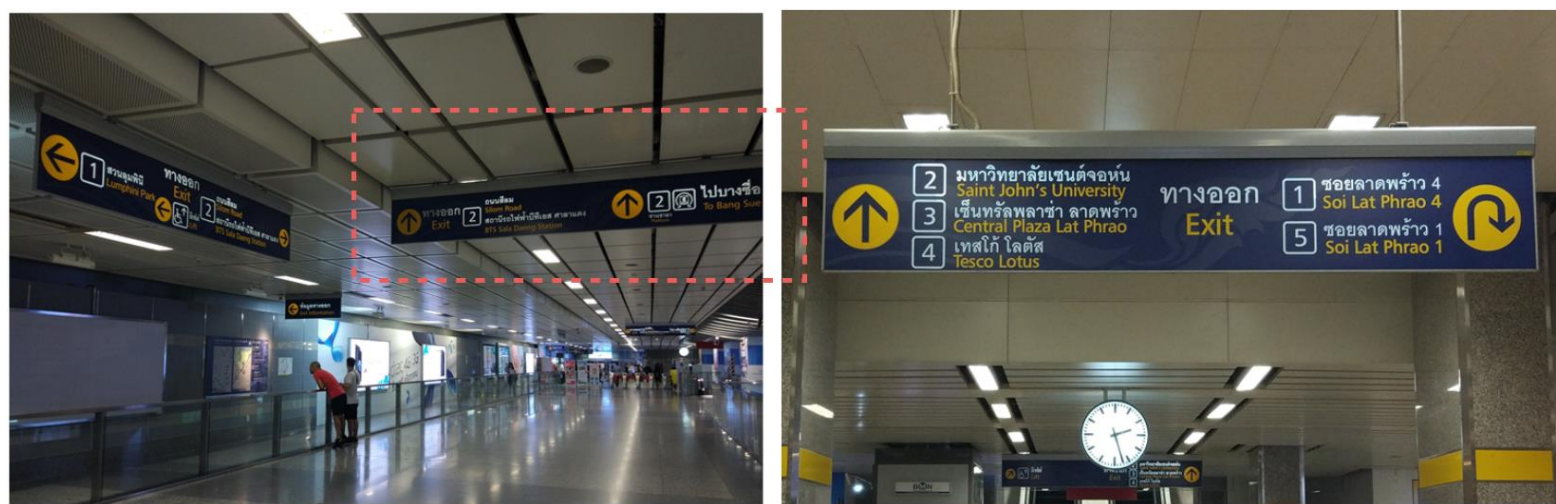

Step 3 Informational sign - In case passengers cannot choose their direction or require more information to choose a number of exit gates from the escalators. 

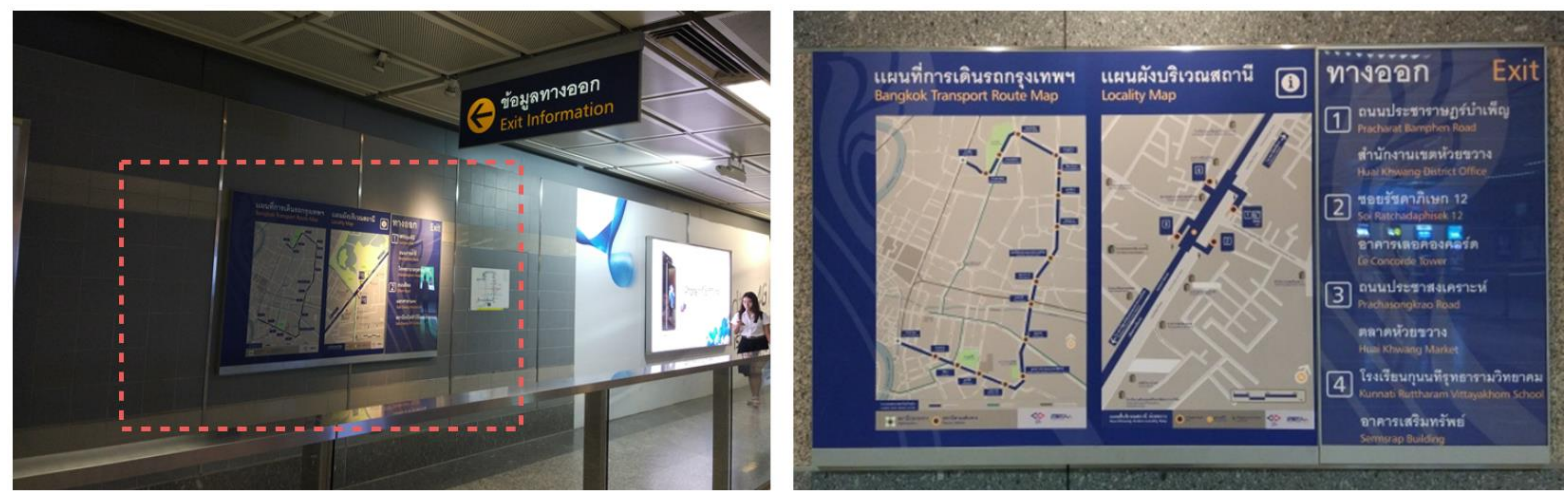

Step 4 Confirmational sign - Confirms the way and guides passengers to the correct exits.
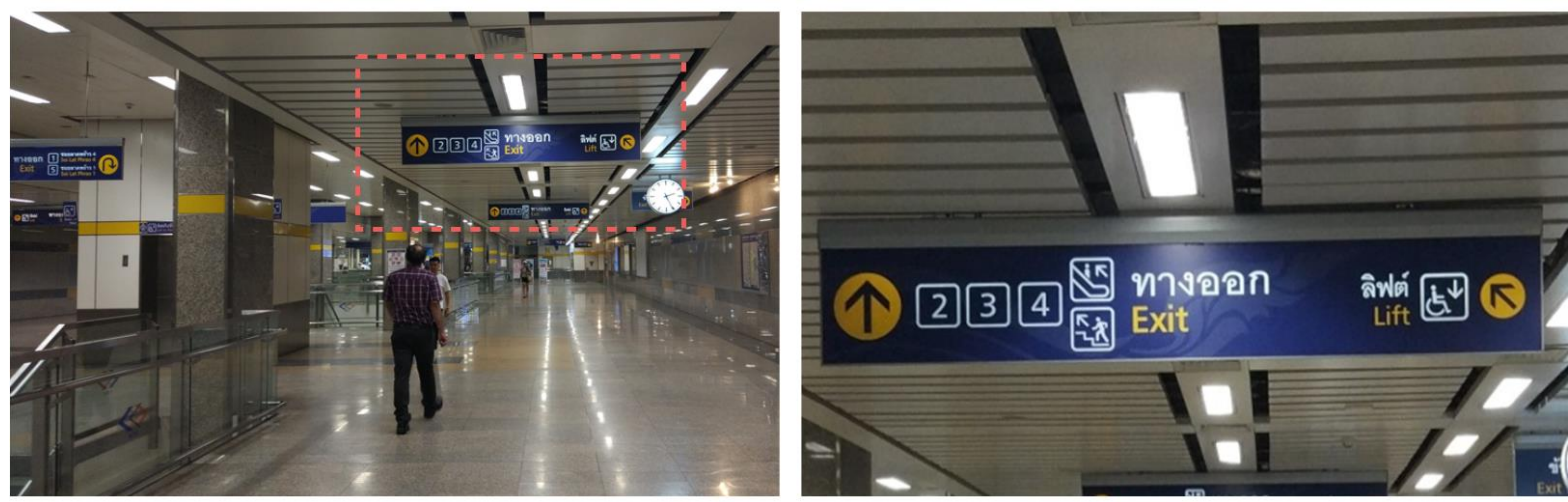

\subsection{Discussion and Analysis}

The survey of the physical stations area of Metropolitan Rapid Transit Chaloem Ratchamongkhon Line (MRT), the route has a total distance of 20 kilometers and 18 stations, which can provide conclusive results of the effects of specific area characteristics according to the structures of the subway stations and types and exits of subway stations had the effects on travelling behaviors and signage for passengers of the subway. Signage that is important to passenger behavior is Step 2: Directional Sign and Step 3: Informational Sign (in the case that passengers cannot choose their direction or require more information) (Pontikakis, Twaroch, 2006) because these signage are used by passengers to make decisions on choosing the correct path and they display behavioral actions which are important decisions for connecting mental information which leads to behavioral action. The finding is consistent with the way-finding process of Arthur and Passini's (1992) study.

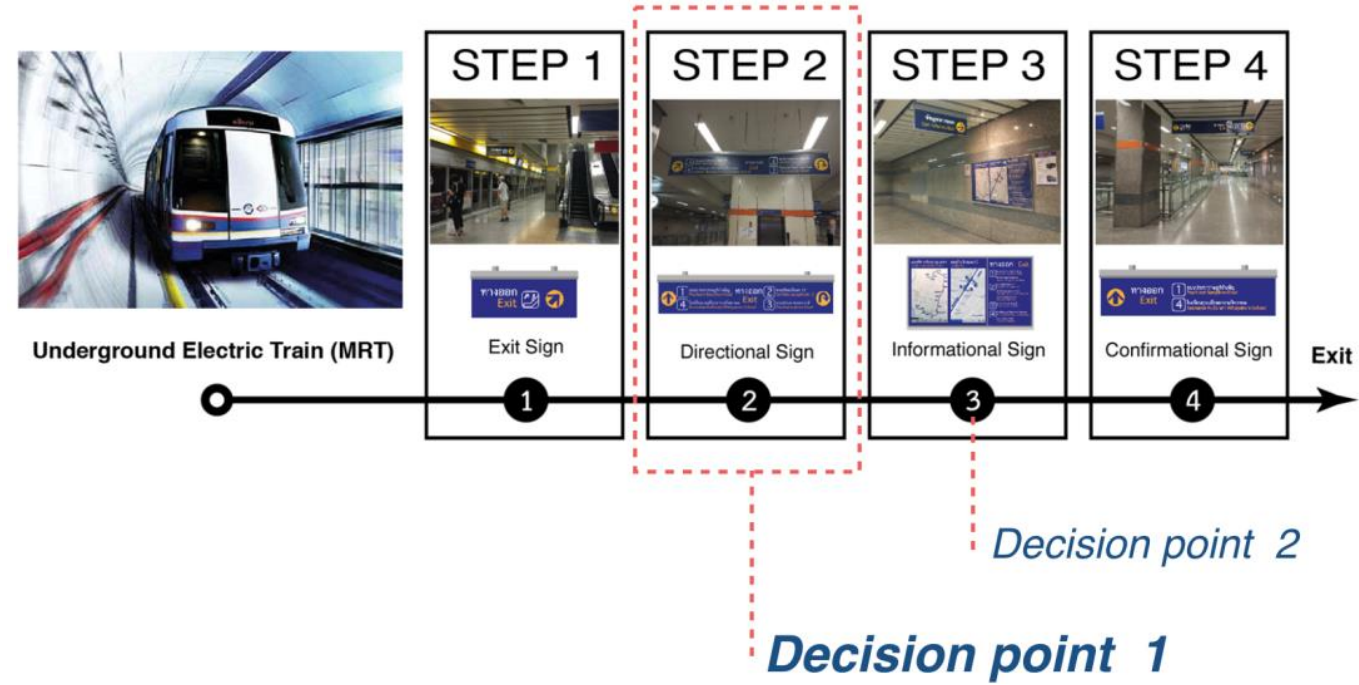

Fig. 10: The diagram showing the steps of decision points for passengers. 
The decision process is hierarchical and structural and requires information from the environment starting from specifying the destination to deciding to act step by step until reaching the destination. The familiarity with the particular environment affects the decision to go to the destination. Going to the destination under an environment that is familiar will be decided by referring to a plan from experience (Arthur and Passini, 1992)

The signage can be divided by the specific type of environment according to the characteristics of the station and the important signage is Directional Sign in Step 2, the arrangement of details and the number of exit gates of the subway station that are not in order $(1,2,3 \ldots)$ and not in the same direction (left - right) (Wells, William, Burnett, \& Moriarty, 1998), and which does not adhere to the Laws of Organization (Crooks \& Stein,1988) such as Law of Similarity is the principle of organizing graphical factors to help humans to perceive sight quickly, and factors to compare shape, size and color, perceived to be the same thing or the same type by humans, Law of Proximity is the principle of organizing minor graphical factors relating to each other to be in a proximate location or a group which creates the visual image, to increase the potential of visual images to communicate meaning, Law of Continuity is the principle of organizing graphical factors by an order of importance according to the way people read directions in different cultures, from left to right and top to bottom, for clear and complete communications, Law of Closure is the principle of organizing graphical factors by reduction of images because in general, people are more familiar with reading an image that is complete than reading an image that is incomplete. The affect perception and insight according to the theory of Gestalt, which can categorize the subway stations into two groups as follows.

Group 1 - Organization of details and numbers of the exit gates that adhere to the theory are Sam Yan station, Si Lom station, Lumphini station, Khlong Toei station, Queen Sirikit National Convention Centre station, Sukhumvit station, Phra Ram 9 station, Sutthisan station, and Bang Sue station, see Fig. 11

Group 2 - Organization of details and numbers of the exit gates that do not adhere to the theory are Hua Lamphong station, Phetchaburi station, Thailand Cultural Centre station, Huai Khwang station, Ratchadaphisek station, Lat Phrao station, Phahon Yothin station, Chatuchak Park station, and Kamphaeng Phet station, see Fig. 12

From our survey, the design errors illustrated in Fig. 12, shown as Group 2, are errors in the organization of details and numerals of the exit gates that did not adhere to the Gestalt theory, i.e. the layout of the gates and their numeral labels did not go well together (see the layout in Fig. 8); the numerals were not in sequential order and the arrow signs were inconsistent with respect to left and right directions (Wells, William, Burnett \& Moriarty, 1998). The design of numeral labels and signage did not take into account passengers' recognition of directions in the station and were not consistent among stations, hence it caused confusion: the inconsistency made it difficult for passengers to recognize and memorize the route that they had to move along in an underground station.

On the other hand, an appropriate environmental graphic design from the initiation of a project that takes into account the layouts of all subway stations including the entrances and exits as well as the interaction between the signage and expected passengers' behaviour should result in less confusion and better recognition.

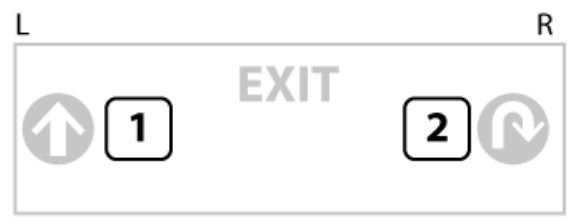

(a)

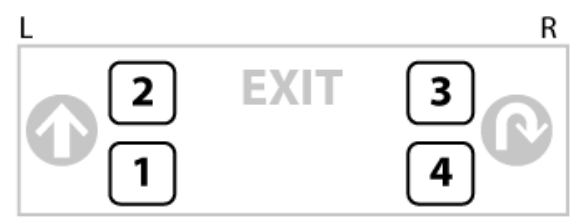

(b)

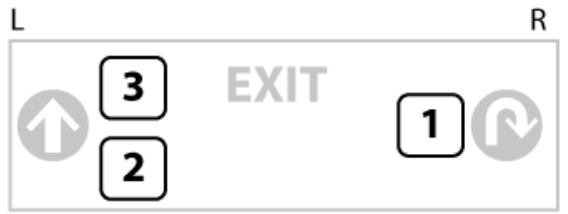

(c)

Fig. 11: Group 1 - Organization of details and numbers of the exit gates that adhere to the theory of Gestalt (Step 2 - Directional sign);

(a) Sam Yan, Si Lom, Khlong Toei, Bang Sue; (b) Lumphini, Sukhumvit, Phra Ram 9;

(c) Queen Sirikit National Convention Centre, Sutthisan; 


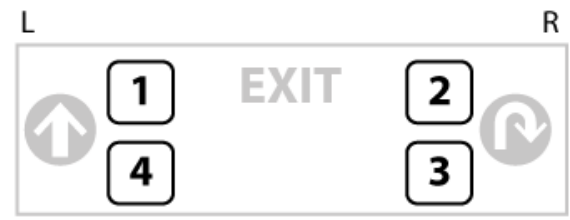

(a)

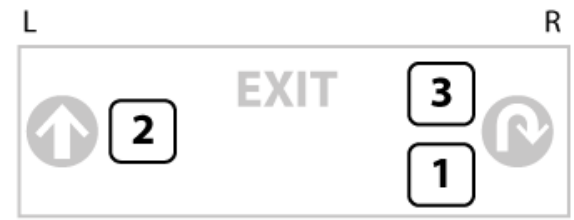

(c)

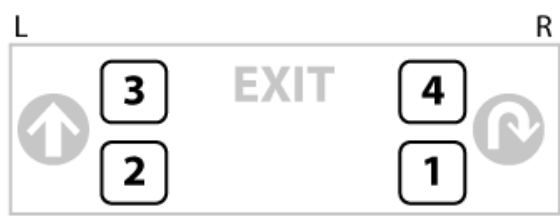

(b)

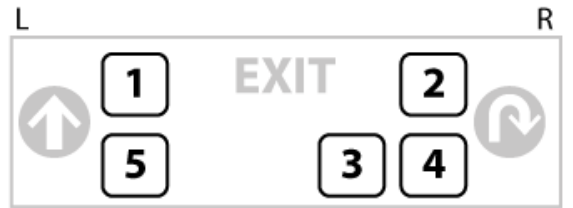

(d)

Fig. 12: Group 2 - Organization of details and numbers of the exit gates that do not adhere to the theory of Gestalt (Step 2 - Directional sign); (a) Hua Lamphong, Ratchadaphisek, Lat Phrao, Chatuchak Park; (b) Phetchaburi, Kamphaeng Phet;

(c) Thailand Cultural Centre, Huai Khwang; (d) Phahon Yothin

\subsection{Conclusion}

The study investigated the physical of Metropolitan Rapid Transit Chaloem Ratchamongkhon Line (MRT) has a total route distance of 20 kilometers and is an underground project containing all the routes of 18 total stations, with an average distance of 1 kilometer between each station, starting from the front of Hua Lamphong railway station and ending at Bang Sue electric train station.

The results demonstrated that the specific area characteristics of the structures of subway stations There are a total of 18 subway stations categorized into three types which are 1) Central platform 2) Side platform 3) Stack platform. Most stations are a central platform The characteristic of each platform depends primarily on their physical limitations. The finding is consistent with the types and exits of subway stations categorized into four types' including (1) two-way directions (2) three-way directions (3) four-way directions and (4) five-way directions for passengers' decision.

The results indicated that probably the influence on the environmental graphic design has affected to the travelers' perception of passengers, four steps can be identified according to the behavioral characteristics and the relationships between signage, including Exit sign, Directional sign, Informational sign and confirmational sign. Therefore signage that is important to passenger behavior is Step 2) Directional Sign and Step 3) Informational Sign (in the case that passengers cannot choose their direction or require more information) the decision process is hierarchical and structural and requires information from the environment starting from specifying the destination to deciding to act step by step until reaching the destination because these signage are used by passengers to make decisions on choosing the correct path and them display behavioral actions which are important decisions for connecting mental information which leads to behavioral action and exit path direction on signage. Which have evidence many differences in physical characteristics and errors in the organization of details and numerals of the exit gates that may cause problem and confusion affected perception and insight according to the gestalt theory toward the recognition of information and the clarity of routing for passengers to decide to the exit of each side.

This latter kind of study and a study of appropriate environmental graphic design for guiding passengers throughout the system are of major significance and should be conducted in the future.

\section{References}

Arthur, P., Passini, R. (1992). Wayfinding: People, Signs, and Architecture. Mc Graw- Hill Ryerson, New York.

Charles Wallschlaeger, C. B.-S. (1992). Basic Visual Concepts and Principles for Artists, Architects and Designers. lowa: Wm. C. Brown.

Crooks, R. L., \& Stein, J. (1988). Psychology: Science, Behavior and Life. Newyork: Rinehart and Winston. einhold, New York.

E. Pontikakis, F. Twaroch. (2006). "Schematic maps as an alternative to point coverages when topographic maps are not available". Proceedings of 10th International Conference on Information Visualization (IV'06), ed. by Banissi, E., pp. 297-303, IEEE Computer Society, London.

Ivan Chermayeff, Chris Calori. (2007). Signage And Wayfinding Design: A Complete Guide to Creating Environmental Graphic Design Systems. p.124.

Jean-Charles Chebat, Claire Gélinas-Chebat and Karina Therrien. (2008). "Gender-related wayfinding time of mall shoppers". Journal of Business Research, Vol 61 , Issue 10, pp.1076-1082

Lester, Martin Paul. (2000). Visual Communication Images with Messages. 2nd ed. California: Wadsworth: Thomson Learning.

Lynch, K. (1960). The Image of the City. Cambridge, Mass. : M.I.T. Press. 
Meng-cong Zheng, Tadao Shimizu, Kiminobu Sato. (2009). "Information Signs Based on Users' Wayfinding Behavior in Transfer between Above-ground Stations". Bulletin of Japanese Society for the Science of Design, Vol. 55, No. 6, p.1-10.

Meng-Cong Zheng. (2012)." Time Constraints in Emergencies Affecting the Use of Information Signs in Wayfinding Behavior”. Social and Behavioral Sciences, 35: 440-448.

Passini, R. (1984). Wayfinding in Architecture. Van Nostrand R.

Pei-Ying Li, Haruo Hibino, Shinichi Koyama, Meng-Cong Zheng. (2012). "Tailoring Map Design Based on Map-Reading and Way- Finding Behaviour in Subway Stations". Procedia-Social and Behavioral Sciences, 42: 466-476.

Weisman J. (1981). "Evaluating architectural legibility-wayfinding in the built environment". Environment and Behavior, 13(2): 189-204.

Wells, William, Burnett, J., \& Moriarty, S. (1998). Advertising Principles \& Practice. 4th ed. New Jersey: Prentice-Hall International.

Zulfadly Azizi Bohari, Syahriah Bachok, Mariana Mohamed OsmanProcedia.(2014). "Improving the Quality of Public Transportation System: Application of simulation model for passenger movement". Social and Behavioral Sciences, 153: 542 - 552 